\title{
FUNDAMENTOS TEÓRICOS DE LA CADENA DE CUSTODIA EN EL PROCESO PENAL CUBANO*
}

\author{
THEORETICAL FOUNDATIONS OF THE CHAIN
OF CUSTODY OF THE EVIDENTIAL ELEMENTS IN \\ THE CUBAN CRIMINAL PROCESS \\ FUNDAMENTOS TEÓRICOS DA CADEIA DE \\ CUSTÓDIA NO PROCESSO PENAL CUBANO
}

\section{RESUMEN}

En el proceso penal, al ocurrir un hecho con caracteres de delito, se valoran como fundamentales todos los aspectos que prueben lo que realmente aconteció, y para ello parte de identificar la evidencia y que ésta sea analizada y conservada hasta el momento de su valoración por el tribunal competente. Es ahí que la cadena de custodia de los elementos probatorios en Cuba se convierte en un tema trascendental para determinar el valor probatorio de éstos, con la garantía de un debido proceso penal.

\footnotetext{
* Artículo de revisión: resultado de proyecto de investigación doctoral donde se expone un escrito tipo informe general de algunos de los avances de la investigación que realizo en Ciencias Penales y Criminológicas.

a. Doctoranda. Especialista en Ciencias Penales y Criminológicas. Profesora de Derecho Penal y Criminalística. Facultad de Derecho, Universidad de la Habana.
}

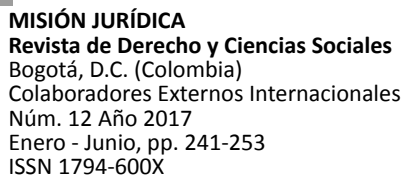




\section{PALABRAS CLAVES}

Delito, proceso, prueba, cadena de custodia, debido proceso.

\begin{abstract}
In the penal process when a crime occurs every aspect that proves what really happened is valued as fundamental. Thus, the evidence has to be identified and analyzed as well as preserved until the moment of its evaluation by a competent court. In Cuba, at that point, the chain of custody of the evidential elements turns into an important matter to determine the probative values of these, with the appropriate penal process as guarantee.
\end{abstract}

\section{KEYWORDS}

Crime, process, proof, chain of custody, due process.

\section{RESUMO}

No processo penal quando um ato com características de crime ocorre são valorizados como fundamentais todos os aspectos que pudessem provar o que realmente aconteceu, começando por identificar as provas e que esta seja analisada e preservada até o momento da sua apreciação pelo tribunal competente. É por isso que a cadeia de custódia das provas em Cuba torna-se uma questão importante para determinar o valor probatório destas, com a garantia do devido processo penal.

\section{PALAVRAS-CHAVE}

Crime, processo, prova Cadeia de custódia, devido processo legal.

\section{INTRODUCCIÓN}

La cadena de custodia es un tema pendiente de estudio para dar respuestas a las interrogantes que sobre la misma existen en todo el proceso de investigación y probanza de los hechos delictivos. Con esta investigación se pretende brindar varios fundamentos desde lo teórico, que implicarían la construcción de un plexo que conjugue adecuadamente la eficacia de los elementos probatorios, sin olvidar las garantías, dúo indisoluble en un debido proceso.

Se valora un análisis teórico sobre la cadena de custodia de los elementos probatorios dentro del proceso penal, distinguiendo la carencia de regulación de un procedimiento sobre la misma en Cuba, que permita que esos elementos que se obtienen relativos a un hecho delictivo lleguen al juicio oral con la debida conservación y valor probatorio, acorde con los principios que informan el proceso. La investigación planteó como problema científico que el insuficiente desarrollo doctrinal en Cuba sobre la cadena de custodia de los elementos probatorios implica una laguna legislativa en el ordenamiento jurídico cubano, con la consiguiente afectación de las garantías de un debido proceso.

El objetivo consistió en fundamentar a partir de los presupuestos teórico - jurídicos propuestos, bases sobre la cadena de custodia de los elementos probatorios en el ordenamiento jurídico cubano, en aras de lograr un debido proceso penal.

La investigación se sustenta en los métodos histórico-lógico, que posibilitó conocer la evolución histórica, el desarrollo y las definiciones que existen sobre el proceso penal, la prueba, fuente de prueba y cadena de custodia, teniendo en cuenta sus elementos fundamentales; el teórico-jurídico, que permitió realizar un estudio de la doctrina existente sobre el proceso penal, la prueba, fuente de prueba, huellas, muestras o evidencias y la cadena de custodia, hasta valorar la carencia de regulación del tema en el ordenamiento jurídico cubano; el exegético-analítico que al ser un método propio de las ciencias jurídicas hizo posible el análisis minucioso de la normativa cubana detectando la carencia de regulación sobre la cadena de custodia de los elementos probatorios en el proceso penal cubano.

Como técnicas de investigación se usaron la revisión bibliográfica y el análisis de documentos, las cuales permiten estudiar y realizar consideraciones de las informaciones recogidas de toda la bibliografía consultada, haciendo posible formar y consolidar los conocimientos, para realizar las valoraciones que contiene la investigación sobre el tema; esto en función de lograr demostrar la necesidad de una normativa cubana en lo relacionado a la cadena de custodia de los elementos probatorios en el proceso penal cubano. 


\section{RESULTADOS}

La tortura y los tratos inhumanos para la obtención de los elementos de prueba llenarían el proceso de ilicitud en un determinado período de tiempo (antes del siglo XIX), ya que la forma de obtenerlas era por medio de la coerción, la coacción y fuerza. La búsqueda de la verdad por medio del tormento es realmente una manera de provocar la aparición de un indicio, el más grave de todos, la confesión del culpable; pero es también la batalla, con la victoria de un adversario sobre el otro, lo que "produce" ritualmente la verdad. En la tortura para hacer confesar hay algo de investigación y hay algo de duelo ${ }^{1}$.

Todo esto quedó atrás con las revoluciones acontecidas en el siglo XIX donde se fue democratizando el proceso penal y con ello los métodos de obtención de los elementos de prueba. Siendo importante señalar que resultado de este propio proceso es que podemos hablar de la cadena de custodia como un proceso continuo y documentado que demuestra la autenticidad de la evidencia. Su importancia está en garantizar a los Tribunales que las evidencias son las mismas recolectadas, acreditando su identidad, estado original, condición y cambios hechos en ellas por cada custodio.

El criminólogo Francés Edmon Locard ${ }^{2}$ en 1910, describió "El principio de intercambio", afirmando que todo criminal en su paso por la escena del delito, deja una parte de sí y se lleva consigo, deliberada o inadvertidamente algo de la propia escena. Locard sostuvo que estos indicios de prueba de su presencia y de la comisión de su conducta delictiva pueden conducirnos a su identificación, desde entonces se procede a recolectar las evidencias materiales o físicas relacionadas con un delito, de cuya existencia, análisis científico, características, o condiciones particulares o relacionadas con otras, se infieren conclusiones que corroboran el hecho punible o

1. FOUCAULT, Michel: Vigilar y Castigar. Nacimiento de la prisión. Siglo veintiuno Editores Argentina. 1976. p. 40

2. El llamado Sherlock Holmes francés: estudió en la Universidad de Lyon, y ahí se licenció en Derecho y se doctoró en medicina. Trabajó como ayudante de otro pionero forense, Alexandre Lacassagne, profesor de medicina forense en la universidad. Continuó en este puesto hasta 1910, cuando fundó el Laboratorio de Criminalística de Lyon. Fue asimismo director del gabinete de la policía de la ciudad. ayudan a explicarlo, mostrándose como material de prueba del hecho.

La cadena de custodia debe garantizar la integridad de la evidencia desde el momento mismo de la recolección, puesto que estos elementos probatorios pueden finalmente convertirse en pruebas cuya legalidad debe estar garantizada para que puedan ser debatidas en el juicio penal.

Polémicas diversas se han suscitado al conceptualizar el termino "cadena de custodia", por lo que en la actualidad se han emitido varios criterios en torno al mismo, moviéndose entre la Criminalística y el Derecho Procesal Penal; de ahí la importancia de referirnos a los aspectos fundamentales sobre su definición.

La cadena de custodia para Cordero Bello, autor dominicano, es un método diseñado para controlar la confiabilidad de la prueba, permite demostrar que el intercambio de evidencia ocurrió realmente en el momento del hecho. Si esto no es así, se pierde el valor probatorio de un elemento de prueba y se habla de contaminación. La cadena de custodia debe garantizar la pureza de la evidencia desde el momento mismo de la recolección, puesto que estos elementos materiales probatorios pueden finalmente convertirse en pruebas cuya legalidad debe estar garantizada para que puedan ser descubiertas y controvertidas en juicio ${ }^{3}$.

Para Hugo Hermoza, autor peruano, cadena de custodia es todo un conjunto de procedimientos de seguridad, destinados principalmente a garantizar que el elemento material probatorio o evidencia física identificado, fijado, recolectado, embalado y rotulado, es el mismo que estaba en el lugar explorado y que se encuentra en igualdad de condiciones fenomenológicas a las que allí tenía ${ }^{4}$.

Por su parte Halanoca la define como un conjunto de procedimientos ineludibles, en los que prima el tema de seguridad. Estos procedimientos se encuentran destinados principalmente a garantizar que el elemento material probatorio o la evidencia física hallada, una vez que ha

3. CORDERO BELLO, Tomas. (mayo 21, 2008): Blog dedicado al desarrollo de la Criminalística y las Ciencias forenses en la República Dominicana. Consultado el 3 de mayo del 2010. Ubicado en URL 
cumplido con sus requisitos (identificación, recolección, embalaje y rotulación) sea la misma que se encontró en la escena del crimen ${ }^{5}$.

Otra definición plantea que la cadena de custodia de la prueba es el procedimiento controlado que se aplica a los indicios materiales relacionados con el delito, desde su localización hasta su valoración por los encargados de administrar justicia y que tiene como fin no viciar el manejo de que ellos se haga y así evitar alteraciones, sustituciones, contaminaciones o destrucciones ${ }^{6}$.

Por su parte Leiva Muñoz ${ }^{7}$, autor español, define la cadena de custodia como aquel conjunto de operaciones policiales y procesales que son oficialmente desarrolladas para la recogida, obtención, conservación y puesta a disposición íntegra del tribunal de enjuiciamiento de todas las pruebas que han sido previamente obtenidas a lo largo de la investigación criminal, con un pleno sometimiento a las reglas del proceso y que sirven para fundamentar la culpabilidad o inocencia de una persona. Se trata, por lo tanto, más que de un concepto, de una praxis adecuada para que la prueba obtenida cumpla su función y pueda cumplirse una de las principales garantías del proceso que es la de valorar aquellas pruebas que fueron obtenidas durante la investigación sumarial, sin género de duda alguno acerca de su autenticidad, una garantía que se extiende sobre las distintas fases del proceso y que debe ser objeto de una continua actualización.

Para el profesor Fernández Romo la cadena custodia es el procedimiento destinado a garantizar la individualización, seguridad y preservación de las huellas, muestras y evidencias, obtenidos en la etapa investigativa con interés criminalístico, en un hecho que reviste caracteres de delito, destinados a garantizar su autenticidad, para los efectos del proceso ${ }^{8}$.

4. HUGO HERMOZA, Orosco Plinio. (2007): "La Cadena de Custodia en el Nuevo Proceso Penal". La Reforma. Perú. Consultado el 18 de febrero del 2012.

5. HALANOCA HUAMÁN, Julián César. (2009): “La escena del delito y la cadena de custodia en el nuevo proceso penal". Reproducido en Agenda Magna el 10 de febrero de 2009. Consultado el 18 de febrero del 2012.

6. BOLETÍN ALERTA. (2011) Nuevo Código Procesal Penal impide mostrar pruebas documentales en etapa de investigación. http:// www.mpfn.gob.pe/prensa-detalle.php?id=5088. Publicado 21 de enero del 2011. Consultad 21 de febrero del 2012
Manuel Restro indica el importante papel que tiene la cadena de custodia sobre

(...) los elementos materiales del delito y la evidencia física y radica en que estas pueden probar la comisión de un delito, relacionar al sospechoso con la víctima o con la escena del crimen, establecer las personas asociadas con el delito, corroborar el testimonio de una víctima, definir el modo de operación del agresor y relacionar casos entre sí o exonerar a un inocente. Además, es más confiable y objetiva que la prueba testimonial, y el desarrollo de la ciencia le ha hecho más importante? .

Angulo indica que la cadena de custodia es la garantía procesal que afirma verazmente que el elemento de prueba en el juicio es el que fue recaudado o practicado, y que su integridad no ha sido sustituida o alterada a lo largo del proceso penal ${ }^{10}$.

Angulo Arana complementa al respecto que:

(...) la cadena de custodia es un procedimiento establecido por la normatividad jurídica, que tiene el propósito de garantizar la integridad, conservación e inalterabilidad de elementos materiales de prueba como documentos, muestras (orgánicas e inorgánicas), armas de fuego, proyectiles, vainillas, armas blancas, estupefacientes y sus derivados, etc.; entregados a los laboratorios criminalísticos o forenses por la autoridad competente a fin de analizar y obtener, por parte de los expertos, técnicos o científicos, un concepto pericial ${ }^{11}$.

En consonancia con lo anterior "Cuando en un hecho de sangre y en la escena se encuentra el instrumento del delito, este instrumento

7. Módulo instruccional: Principios jurídicos relacionados con la investigación y la cadena de custodia. Impartido por José Luis Leiva Muñoz, Fiscal Tribunal Supremo de Justicia, Andalucía España. 5 - 16 de mayo del 2008 Tegucigalpa. Ubicado en URL. Consultado el 27 de diciembre del 2010.

8. FERNANDEZ ROMO, Rodolfo. (2011): "La Prueba Pericial y el debido proceso penal". Revista Científica Equipo Federal del Trabajo. ISSN 1609 3031. Septiembre de 2011.Catalogada en Latindex desde 2005; http://www.newsmatic.e-pol.com.ar/ index.php?

9. RESTREPO MEDINA, Manuel. (2005): "El Nuevo sistema acusatorio". Bogotá, Colombia, Edit. Intermedio, p.39

10. ANGULO, Rubén Darío. (2005): La Cadena de Custodia en Criminalística, Ediciones Doctrina y Ley Ltda. Bogotá D.C Colombia, p. 1 y 2 
empleado por el delincuente, desde que se ha comprobado el hecho y es hallado, ya rige la cadena de custodia"12.

Como se puede apreciar, en las acepciones citadas existen aspectos comunes que nos permitirían proponer una definición con estos elementos similares así:

I. Es un sistema, procedimiento ó conjunto de procedimientos.

II. a través del cual se va a recolectar, fijar, levantar y analizar los elementos probatorios del lugar donde ocurre un delito o de otros asociados a éste.

III. en la investigación penal de hechos con caracteres de delito.

IV. para garantizar la individualización, autenticidad, seguridad, preservación e integridad de dichos elementos probatorios.

Para esta investigación la cadena de custodia es el proceso que va desde la fijación, levantamiento, análisis y conservación de las huellas, muestras o evidencias relativas a un hecho delictivo, hasta su valoración en el acto del juicio oral, garantizando la autenticidad y legitimidad de cada elemento probatorio en el proceso penal.

Es importante tener en cuenta algunos apuntes sobre lo expuesto en las legislaciones sobre cadena de custodia: (i) se regula en leyes ó reglamentos destinados a mantener la fuerza o calidad probatoria de las evidencias encontradas en el lugar de los hechos delictivos ó en otros relacionados a éste. (ii) Sólo Colombia establece en su ley adjetiva lo relativo a la cadena de custodia, y como ejemplo de reglamento tenemos el caso de Perú. (iii) De la revisión de catorce códigos de procedimiento penal ${ }^{13}$,encontramos que sólo uno (Código de Procedimiento Penal de Colombia ${ }^{14}$ ) regula la cadena de custodia, en su artículo $205^{15}$ se refiere a cómo deben someterse a cadena de custodia todos los elementos materiales y evidencia física que se obtenga de los actos de investigación, para más adelante en el artículo $216^{16}$ expone los

11. ANGULO ARANA, Pedro. (2006): La Investigación del Delito en el Nuevo Proceso Penal. Lima, Gaceta Jurídica S.A.175p., citando a LOPEZ CALVO, Pedro y GOMEZ SILVA, Pedro (2000) Investigación Criminal y Criminalística. Bogotá, Colombia, Temis, p.137

12. MANUAL DE CRIMINALÍSTICA DE LA POLICÍA NACIONAL DEL PERÚ; primera edición Lima, p.45 aspectos sobre el aseguramiento y custodia de los elementos que se obtengan de la investigación, siempre teniendo en cuenta las reglas de la cadena de custodia; para dedicar luego su capítulo cinco a la cadena de custodia de sus diferentes aspectos considerar, desde el artículo 254 al 266, dejando preceptuado la aplicación, responsabilidad, inicio de la cadena de custodia, traslado, actuación del perito, identificación, certificación y destino de los elementos de prueba relacionados a un hecho delictivo. (iv) Es importante observar como la propia ley refiere la importancia de la cadena de custodia y resalta cada aspecto a valorar. (v) En las leyes adjetivas de los otros países estudiados sólo se establecen los medios de prueba, así como su pertinencia y valoración, la licitud de la prueba, la actuación del Ministerio Público, así como los diferentes actos de investigación.

Sin embargo, se pudo valorar que existen reglamentos ó leyes especiales que recogen la cadena de custodia de las huellas, evidencias o muestras de los hechos delictivos, estableciendo

13. Fueron revisados catorce códigos de procedimiento penal, los cuales se mencionan a continuación: Código de procedimiento penal de Bolivia, Ecuador, Guatemala, Nicaragua, Venezuela, Perú, Chile, Paraguay, México, El Salvador, Costa Rica, República Dominicana y Colombia.

14. Código de Procedimiento Penal de Colombia, Ley No. 229 del 2004.

15. Artículo 205: Actividad de policía judicial en la indagación e investigación. Los servidores públicos que, en ejercicio de sus funciones de policía judicial, reciban denuncias, querellas o informes de otra clase, de los cuales se infiera la posible comisión de un delito, realizarán de inmediato todos los actos urgentes, tales como inspección en el lugar del hecho, inspección de cadáver, entrevistas e interrogatorios. Además, identificarán recogerán, embalarán técnicamente los elementos materiales probatorios y evidencia física y registrarán por escrito, grabación magnetofónica o fonóptica las entrevistas e interrogatorios y se someterán a cadena de custodia. Cuando deba practicarse examen médico legal a la víctima, en lo posible, la acompañará al centro médico respectivo. Si se trata de un cadáver, éste será trasladado a la respectiva dependencia del Instituto Nacional de Medicina Legal y Ciencias Forenses o, en su defecto, a un centro médico oficial para que se realice la necropsia médico legal. Sobre esos actos urgentes y sus resultados la policía judicial deberá presentar, dentro de las treinta y seis (36) horas siguientes, un informe ejecutivo al fiscal competente para que asuma la dirección, coordinación y control de la investigación. En cualquier caso, las autoridades de policía judicial harán un reporte de iniciación de su actividad para que la Fiscalía General de la Nación asuma inmediatamente esa dirección, coordinación y control.

16. Artículo 216. Aseguramiento y custodia. Cada elemento material probatorio y evidencia física recogidos en alguna de las inspecciones reguladas en los Artículos anteriores, será asegurado, embalado y custodiado para evitar la suplantación o la alteración del mismo. Ello se hará observando las reglas de cadena de custodia. 
las pautas fundamentales para que estas lleguen al juicio oral y se conviertan en pruebas. Es así como sucede en Perú ${ }^{17}$ donde se establece un reglamento para la cadena de custodia, que derivado de su código procesal deja en manos de la Fiscalía dictar dicho reglamento, donde en su artículo 7 se conceptualiza la cadena de custodia como "el procedimiento destinado a garantizar la individualización, seguridad y preservación de los elementos materiales y evidencias, recolectados de acuerdo a su naturaleza o incorporados en toda investigación de un hecho punible, destinados a garantizar su autenticidad, para los efectos del proceso". Además, regula el procedimiento, formato, supervisión, así como los responsables y sus obligaciones, entre otros aspectos de vital importancia.

Apremia entonces referir de forma general a las denominadas etapas o fases de la cadena de custodia, a través de las cuales se demuestra la autenticidad de los elementos probatorios, que lo hallado en el lugar de los hechos es igual a lo valorado por el juez en el juicio oral. A nuestra consideración existen siete etapas o fases, las cuales enumeramos como:

1.- Hallazgo y custodia del Lugar del Hecho o Escenario del Crimen: debiendo interpretarse el lugar del hecho desde un punto de vista amplio, ya que la determinación de los indicios no necesariamente se ajusta al lugar principal donde sucedió el hecho investigado o donde están la mayoría de indicios, sino que también estos pueden estar dispersos por varios lugares, o inclusive sobre el mismo cuerpo de la víctima o del sospechoso, estando todos sometidos a las mismas reglas de custodia. Los actos a realizarse en el lugar de los hechos son definitivos, de ahí que se proteja estrictamente para que no sean alterados porque no podrán ser obtenidos en otro momento.

La custodia inmediata del lugar del suceso evita que personas ajenas a la investigación enmascaren la zona, destruyendo o alterando los indicios relevantes para la investigación; pues, con la custodia del lugar del suceso se inicia también la custodia de las evidencias materiales. Custodiar significa impedir el acceso a sujetos extraños, o bien, limitar la cantidad de los mismos oficiales del orden público en el sitio, ya que de esta forma

17. Reglamento de la Cadena de Custodia de Elementos Materiales, Evidencias y Administración de Bienes Incautados (Aprobado por Resolución No 729-2006-MP-FN del 15.junio.2006) también es posible que evitar la alteración o destrucción de la evidencia.

2.- Inspección preliminar y búsqueda de indicios: una vez ubicado y debidamente custodiado el escenario del crimen, es importante la designación de un oficial de investigación que sea el administrador del procesamiento del sitio, es decir, una persona con vasta experiencia que asuma un rol de liderazgo con los demás compañeros y que se encargue de coordinar con el instructor del caso los procedimientos técnicos que se van a seguir en la búsqueda de los indicios materiales.

El éxito de las técnicas de la criminalística utilizadas en la búsqueda científica de los elementos probatorios, no solo depende de la naturaleza del lugar del hecho delictivo, sino también, depende en buena medida de la capacidad profesional de la persona asignada para el proceso de aplicación de la técnica en cuestión.

3.- Fijación de la huella o evidencia: esta etapa permite determinar con exactitud la ubicación y estado de los indicios que son de interés para la investigación, y que han sido encontrados en el lugar del suceso, lo que facilita la elaboración de versiones y una eventual reconstrucción de los hechos, si en algún momento del proceso surge la necesidad de comprender la dinámica del suceso histórico, lo cual se podrá constatar con las precisas descripciones que deben contener los documentos respectivos.

Si se combinan diversos tipos de fijación sobre la evidencia, la certeza probatoria que se pretenda establecer sobre los mismos en juicio será mayor, ya que ninguno de ellos es excluyente entre sí, sino que se complementan. Ya localizados los indicios dentro del lugar del suceso, las formas más comunes y legalmente permitidas para ser fijados son: la fotografía, el video, el croquis y el acta.

Esta fase resulta de gran importancia para el momento en que se proceda a la valoración de la prueba en juicio. Existe la posibilidad de desvirtuar la calidad de la investigación o determinado testimonio si existen contradicciones entre lo fijado o lo descrito en el informe pericial, y lo relatado por el testigo sobre dicho acto; sin embargo, ésta etapa también puede ser muy importante para resaltar la credibilidad o la confianza sobre el medio de prueba que interese, si todo resulta coincidente. 
4.- Recolección de las evidencias: en esta fase, adquieren relevancia la capacitación y los conocimientos técnicos de la persona encargada de extraer o levantar las huellas, muestras o evidencias, ya que de la destreza, sagacidad y cuidado con que se actúe dependen las posibilidades de conservación de la misma.

Respecto al proceso de extracción u obtención de la huella o evidencia, debe tenerse en cuenta que para levantar cada evidencia hay una técnica científica específica que evita su destrucción o alteración. Dominar los diversos tipos de técnica y saber en qué momento deben aplicarse es fundamental en cualquier investigación pericial, si se tiene en cuenta que ese acto de investigación será utilizado como elemento de prueba que permite sostener una eventual acusación.

Es importante mencionar que la construcción de la cadena de custodia no se limita a las huellas, muestras o evidencias recopiladas en el lugar del suceso, entendido en estricto sentido, sino que también se deben controlar las que se obtengan en otros lugares o escenas secundarias, como por ejemplo al propio acusado cuando los lleve consigo, también cuando se trata de muestras o fluidos tomados directamente del cuerpo del propio acusado o la víctima, tales como pelos, sangre o semen, o en el lugar donde se trasladó el cadáver o el producto del delito, entre otras.

Las huellas o evidencias obtenidas deben ser clasificadas e individualizadas cuidadosamente, es decir, inventariadas científicamente, ya que de esta manera no sólo se controla cada uno por separado, sino que también se evita que se confundan entre sí, lo que favorece el proceso de estudio, análisis y comparación que pueda hacerse en el laboratorio, sin margen a error.

5.- Embalaje de la huella o evidencia: tiene como fin principal individualizar y garantizar la integridad de lo ocupado, motivo por el cual el embalaje debe realizarse con una calidad tal que evite su alteración o destrucción, ya sea por la manipulación de la cual es objeto, o por las condiciones de temperatura y humedad que puedan afectar o alterar las cualidades del contenido; también, el embalaje tiene como objetivo evitar que terceras personas puedan alterar o sustituir su contenido.

El embalaje está integrado por el empaque, el sellado y el etiquetado, en consecuencia, cualquiera de los tres que sea inconsistente podría afectar la totalidad del embalaje, así como la confianza absoluta que se requiere sobre el mismo y sobre el indicio que protege.

En relación con el empaque, debe indicarse que el mismo consiste en el envoltorio o recipiente que se utiliza para depositar la evidencia. El sellado tiene como función evitar al máximo cualquier riesgo de que el empaque se abra y, en caso de que eso suceda por cualquier razón, es necesario que queden señales en el empaque, o en el propio sellado, que permitan corroborar cualquier probabilidad de remoción anómala o casual.

La importancia del etiquetado radica en la necesidad de identificar el material probatorio y evitar errores forenses; la información contenida en el etiquetado va a individualizar la evidencia y su origen, con lo cual se evitará el riesgo de que la misma se confunda con pruebas de otros procesos.

Además, cuando se utilizan etiquetas con espacio para registrar los nombres de las personas que reciben y entregan la misma, se puede determinar con exactitud quienes intervinieron en el transporte de la misma y en qué fechas. En el caso de que en forma paralela se lleven actas de estos movimientos, el contenido de las etiquetas permite la confrontación con estas y su veracidad.

Al igual que sucede en la etapa de obtención, la técnica del embalaje está supeditada a la naturaleza del indicio que se pretende proteger y preservar. Así, por ejemplo, las diferencias de embalaje van a ser sustanciales cuando se trata de indicios provenientes del narcotráfico, de un desastre incendiario, residuos biológicos, huellas digitales, o huellas de calzado, casquillos, etc.

6.- Traslado y entrega de la evidencia: como se indicó anteriormente, la información del etiquetado y de las actas permite precisar las personas que transportaron la evidencia, así como también las fechas y los despachos en que estuvo custodiada, debido a que es muy común que los indicios sin embalar o ya embalados se depositen provisionalmente en lugares inadecuados e insospechados o, bien, no se entregan con prontitud al Laboratorio forense (sangre, semen, etc.), lo que eventualmente podría ser la explicación lógica de alguna alteración.

La etapa de la entrega comprende cada una de las entregas y recepciones que se suscitan en 
el transcurso de la manipulación de la evidencia, es decir, resulta cotidiano que una evidencia pase por las manos de varias personas y por diferentes oficinas, sujetos estos a quienes excepcionalmente se les puede hacer llamar para rendir testimonio en el proceso penal, motivo por el cual debe registrarse muy claramente esa identificación en las etiquetas o en las actas que se llevan con ese fin.

7. - Análisis pericial: la evidencia de interés criminalístico levantada u obtenida en el lugar del suceso, o en otros relacionados a éste, debe ser trasladada hasta el Laboratorio de criminalística para que el personal especializado rinda un dictamen pericial que incluya el resultado del análisis practicado.

La relevancia del nexo causal entre la pericia forense y la cadena de custodia, se sustenta en el hecho de que el dictamen rendido debe describir con detalle el estado en que se encontraba la evidencia cuando se recibió para su estudio, así como también el estado del embalaje, de manera tal que se posibilite cualquier confrontación con lo descrito en los registros de la cadena de la prueba o con los testimonios de quienes tuvieron bajo su custodia la misma, principalmente si se detectan diferencias entre lo que obra obtenido, lo remitido y lo analizado en el Laboratorio.

Los peritos desarrollan su actividad científica con equipos y medios tecnológicos de avanzada, es poco común que alguien se cuestione acerca de la calidad, el mantenimiento o la adecuada calibración de esos medios técnicos, lo cual es muy importante para que los resultados sean confiables y fieles con la realidad, en el caso contrario la destrucción o alteración de la evidencia podría darse en el propio Laboratorio si este no cumple con las normas de calidad exigidas. Luego es de notar la Devolución o destrucción de las evidencias: las evidencias recibidas en el Laboratorio de criminalística deben ser custodiadas de ser posible en similares condiciones en las que fueron recibidas, no pueden ser destruidas o alteradas, pues puede interesarse un nuevo peritaje sobre dichas muestras.

Y en el caso del Registro documental de las etapas: se valora como una línea transversal que atraviesa todas las fases o etapas de la cadena de custodia de la huella o evidencia, debido a que de todo cuanto se hace debe quedar algún registro referencial, que analizado en forma independiente o confrontado con las declaraciones de las personas que intervinieron en la investigación, no debe permitir ninguna duda en relación con su tratamiento y manipulación, es decir, debe existir clara constancia de que se trata de una investigación pericial de naturaleza estrictamente científica.

En caso de alteración o suplantación de alguna de estas etapas o fases estaríamos en presencia de la falta de licitud del medio de prueba a utilizar en el proceso penal, pudiendo llevar a una actividad procesal defectuosa o a la nulidad de facto, ya que los elementos levantados y analizados carecerían de valor probatorio, rompiendo con el principio de legalidad de los actos procesales que debe existir en todo el proceso penal.

\section{El proceso penal cubano y la cadena de custodia}

En Cuba con la Ley de Enjuiciamiento Criminal española ${ }^{18}$, se establecía un proceso penal mixto, con elementos predominantes del sistema acusatorio, y garantías para el acusado, que desde su precepto $326^{19}$ normaba la recogida y conservación de los vestigios dejados por el delito en cuestión. Dicha ley fue sustituida por la Ley No. 1251 de 1973 que, si bien mantuvo la esencia de la anterior, introdujo cambios procesales, entre ellos la eliminación de la figura juez de instrucción que fue sustituido por la policía, con toda la investigación e instrucción de los procesos, asesorada y dirigida por el fiscal, figura que también tomó independencia y relevancia con dicha normativa.

18. Ley de Enjuiciamiento Criminal, Real decreto de 14 de septiembre de 1882, Ministerio de Gracia y Justicia «BOE» núm. 260, de 17 de septiembre de 1882 Referencia: BOE-A-1882-6036.

19. Artículo 326: Cuando el delito que se persiga haya dejado vestigios o pruebas materiales de su perpetración, el Juez instructor o el que haga sus veces ordenará que se recojan y conserven para el juicio oral si fuere posible, procediendo al efecto a la inspección ocular y a la descripción de todo aquello que pueda tener relación con la existencia y naturaleza del hecho. A este fin, hará consignar en los autos la descripción del lugar del delito, el sitio y estado en que se hallen los objetos que en él se encuentren, los accidentes del terreno o situación de las habitaciones y todos los demás detalles que puedan utilizarse, tanto para la acusación como para la defensa. Cuando se pusiera de manifiesto la existencia de huellas o vestigios cuyo análisis biológico pudiera contribuir al esclarecimiento del hecho investigado, el Juez de Instrucción adoptará u ordenará a la Policía Judicial o al médico forense que adopte las medidas necesarias para que la recogida, custodia y examen de aquellas muestras se verifique en condiciones que garanticen su autenticidad, sin perjuicio de lo establecido en el artículo 282. Ley de Enjuiciamiento Criminal, Rea decreto de 14 de septiembre de 1882 ...cit. 
Con el proceso de institucionalización de la Revolución cubana, entra en vigor la Ley No. 5 de 1977, Ley de Procedimiento Penal, la cual implantó algunas modificaciones, precisando la figura del instructor policial, las funciones del fiscal como controlador de la fase preparatoria, entre otros aspectos. Esta ley se mantiene vigente hasta hoy con algunas modificaciones con el Decreto Ley No. 128/1991 y el Decreto Ley No. 151/1994.

En la actualidad, esta Ley de procedimiento penal $^{20}$ que se fundamenta en un sistema mixto de enjuiciar, con caracteres del inquisitivo en la fase preparatoria y del acusatorio en el juicio oral, establece sobre la etapa sumarial o investigativa en su artículo 104, según el cual constituyen la fase preparatoria las diligencias previas a la apertura del juicio oral dirigidas a averiguar y comprobar la existencia del delito y sus circunstancias, recoger y conservar los instrumentos y pruebas materiales de éste y practicar cualquier otra diligencia que no admita dilación, de modo que permitan hacer la calificación legal del hecho y determinar la participación o no de los presuntos responsables y su grado, y asegurar, en su caso, la persona de éstos.

Dicha ley adjetiva dispone que esta fase inicial está compuesta por las diligencias previas al juicio, encaminadas a corroborar que sucedió un hecho delictivo, y además recoger y conservar los instrumentos y elementos de prueba, refiriéndose así al levantamiento y preservación del material probatorio, que demuestra la ocurrencia del mismo. Sin embargo, no existe precepto alguno que regule cómo proceder para que todos esos elementos de prueba se recojan, cuiden, conserven y analicen, hasta llegar al juicio oral de forma segura, y convertirse o no en prueba.

En todo el proceso de averiguaciones e investigación, a partir de que se conoce la existencia de un hecho delictivo, es el instructor

20. Ley No. 5 de Procedimiento Penal. Puesta en vigor el 13 de agosto de 1977. Artículo 104: Constituyen la fase preparatoria la diligencias previas a la apertura del juicio oral dirigidas a averiguar y comprobar la existencia del delito y sus circunstancias, recoger y conservar los instrumentos y pruebas materiales de éste y practicar cualquier otra diligencia que no admita dilación, de modo que permitan hacer la calificación legal del hecho y determinar la participación o no de los presuntos responsables y su grado, y asegurar, en su caso, la persona de éstos. el responsable, mientras que el Fiscal actúa como garante de la legalidad y controlador de la actividad de instrucción, y tiene además determinadas facultades decisorias respecto a acciones que deben realizarse o para cuya ejecución se necesita la aprobación o la decisión de éste ${ }^{21}$.

En cuanto a las acciones de instrucción de la fase preparatoria, la primera que se regula en la ley de procedimiento es la inspección del lugar de los hechos (artículo 125 22 ) que, como su nombre indica, se refiere a la observación, empleando todos los sentidos humanos e instrumentos y otros medios que amplían las capacidades y posibilidades de nuestros sentidos, permitiendo descubrir, revelar, fijar y levantar, las fuentes de prueba que puedan ser hallados en el lugar donde se cometió un hecho delictivo, y que sean de posible utilidad para la investigación. El responsable de la práctica de esta diligencia es el instructor, quien debe practicarla de inmediato al tener conocimiento de un delito e, igualmente, señala que hará consignar en las diligencias (protocolos, actas) la descripción del lugar del delito en que se hayan descubierto sus pruebas, el sitio y estado en que se hallen los objetos, y todos los demás detalles que pudieran servir tanto para la acusación como para la defensa. El propio artículo señala que, salvo que se trate de prestar socorro a la víctima, ninguna persona podrá realizar en dichos lugares manipulación o acto de clase alguna que pueda variar las circunstancias del lugar o los objetos que en él se encuentren ${ }^{23}$.

En el artículo $135^{24}$, sobre el cuerpo del delito, se comprende la recogida de las armas,

21. Cfr. CANDIA FERREIRA, José: Ponencia La fase preparatoria del juicio oral. CD Evento IV Escuela de Verano de La Habana sobre Temas penales contemporáneos, Julio del 2008, p. 1. La regulación de las averiguaciones a realizar a partir del conocimiento de un hecho delictivo, es indispensable por dos razones esenciales: como se pretende demostrar la existencia y características de un hecho ocurrido en el pasado, resulta necesario obtener los elementos que permitan formar convicción acerca de tal acontecimiento y mientras más abundantes puedan ser aquéllos, más firme podrá ser el real conocimiento del hecho y sus responsables. Pero por otra parte, para la comprobación de los hechos es necesario que las acciones realizadas cumplan determinados requisitos formales para que tengan la mayor fiabilidad posible $y$, además, que se realicen sin innecesario menoscabo de las garantías legales respecto a los derechos de los ciudadanos $y$, en particular, del derecho de los que resulten acusados a una defensa efectiva.

22. Ley de procedimiento penal (actualizada). Puesta en vigor el 13 de agosto de 1977. Editora "My. Gral. Ignacio Agramonte y Loynaz", Mayo del 2012. Artículo 125. 
instrumentos o efectos de cualquier clase que guarden relación con el delito y se hallen en el lugar donde éste se cometió, en sus inmediaciones, en poder del acusado o en otra parte. Una vez ocupados por el agente actuante, aquel levantará acta de ello, consignando las características del objeto, en poder de quién o en qué lugar se ocupó, estado de conservación, debiendo tomarse las precauciones necesarias para su conservación y posterior identificación según su naturaleza. Ejemplo: el dinero, las alhajas y las obras de arte serán remitidas al Banco; las armas de fuego, después de peritadas, serán remitidas a la autoridad competente; las drogas, sustancias sicotrópicas o de efectos similares serán incineradas. Todas ellas se rigen por disposiciones especiales que deben ser tenidas en cuenta. De ello siempre se dejará constancia mediante el acta correspondiente $y$, cuando sea posible, la ocupación se hará siempre en presencia de testigos que firmarán como constancia ${ }^{25}$.

Durante las investigaciones es posible dejar en calidad de depósito a sus poseedores o propietarios - con las pertinentes prevenciones —, los bienes ocupados. Si se trata de bienes cuya custodia está regulada por disposiciones especiales; a saber, dinero, alhajas, obras de arte, o armas, se atenderá a dichas normas. Los bienes ocupados, que no guarden relación con el delito investigado, se dejarán a la libre disposición del legítimo dueño o poseedor. Igualmente debe tenerse en cuenta el Acuerdo No. 29, de 9 de febrero de 1988 (aclarado por el Acuerdo No. 19, de 14 de febrero de 1989)

\section{Vid. CANDIA FERREIRA, José...cit.}

24. Ley de procedimiento penal (actualizada). Puesta en vigor el 13 de agosto de 1977. Editora "My. Gral. Ignacio Agramonte y Loynaz", Mayo del 2012. Artículo 135. Cfr. RIVERO GARCÍA, Danilo: op. cit., p. 91. Al comentar el artículo 135 a través de las disposiciones como la instrucción No. 40 de 1974 sobre Cuidado, conservación y control de las piezas de convicción en el Tribunal, el Dictamen No. 57. Acuerdo No. 125, de 20 de marzo de 1979 sobre el Destino de la droga ocupada, expone que la autoridad encargada de instruir la fase preparatoria, recogerá las piezas de convicción, conservándolas para que puedan ser identificadas en cualquier momento; por ejemplo, en el juicio oral (artículo 309). Si lo ocupado fuera droga el Tribunal que conozca de la causa, por razones de seguridad, podrá disponer la destrucción de la misma a solicitud del Fiscal, siempre que se conserve una muestra del producto a los fines precedentemente expuestos. El Dictamen No. 420. Acuerdo No. 278, de 11 de diciembre de 2002 sobre el Destino de los bienes ocupados durante las investigaciones.

25. Cfr. HERNÁNDEZ DE LA TORRE, Rafael: Criminalística. Universidad de La Habana, Facultad de Derecho, 2006, p. 95. en lo que respecta a Piezas de convicción donde se determina que en el acta de ocupación se describirán los bienes con toda minuciosidad y detalle, correspondiéndose estos fielmente con los relacionados en las diligencias de depósito. En caso de incineración o destrucción, en el acta ha de constar la autoridad que lo dispone, el motivo, los testigos y demás datos .

El tema planteó un análisis teórico sobre la cadena de custodia de los elementos probatorios dentro del proceso penal, distinguiendo la carencia de regulación de un procedimiento sobre la misma en Cuba, que permita que esos elementos que se obtienen relativos a un hecho delictivo lleguen al juicio oral con la debida conservación y valor probatorio, acorde con los principios que informan el proceso.

Lo anterior conduce a plantear el insuficiente desarrollo doctrinal en Cuba sobre la cadena de custodia de los elementos probatorios lo cual implica un vacío legislativo en el ordenamiento jurídico cubano, con la consiguiente afectación de las garantías de un debido proceso.

No debe perderse de vista que, en la actualidad, una muestra de pelo, fluidos corporales, exámenes de alcoholemia o sustancias estupefacientes, sometidos a peritación científica, tienen un valor probatorio indiscutible. Aunque en un sistema acusatorio formal o mixto prima el principio de libre valoración de las pruebas, no se debe perder de vista que esos elementos son claves y en muchos casos constituyen la base de la decisión final, de ahí su importancia.

\section{CONCLUSIONES}

Los aspectos más relevantes que nos llevan a establecer fundamentos teóricos de la cadena de custodia de los elementos de prueba en Cuba son:

-Es solo a partir del siglo XX que se puede hablar de cadena de custodia de los elementos de prueba en el proceso penal, pues los adelantos de la época hicieron que el lugar del suceso, y todo lo derivado del mismo, fuera valorado por especialistas de diversas ciencias que se encargaron del levantar esas huellas, muestras y evidencias hasta su análisis pericial.

26. Cfr. RIVERO GARCÍA, Danilo...cit. p. 92. 
- La cadena de custodia es el proceso que va desde la fijación, levantamiento, análisis y conservación de las huellas, muestras o evidencias relativas a un hecho delictivo, hasta su valoración en el acto del juicio oral, garantizando la autenticidad y legitimidad de cada elemento probatorio en el proceso penal.

- Que la cadena de custodia se regula en ley o reglamentos destinados a mantener la fuerza o calidad probatoria de las evidencias, huellas o muestras halladas en el lugar de los hechos delictivos ó en otros relacionados a éste. Que sólo Colombia establece en su ley adjetiva lo relativo a la cadena de custodia, y como ejemplo de reglamento tenemos el caso de Perú.

- La cadena de custodia cuenta con las etapas o fases a través de las cuales se demuestra la autenticidad de los elementos probatorios, bajo el supuesto de que lo hallado en el lugar de los hechos es igual a lo valorado por el juez en el juicio oral.

- Existe un vacío legislativo en el ordenamiento jurídico cubano en cuanto al tema de la cadena de custodia de los elementos probatorios, lo que provoca una luctuosa grieta entre realidad y legislación vigente.

- Finalmente es necesario concluir que la cadena de custodia posee vital importancia por cuanto los elementos que se obtienen inicialmente en el lugar del suceso o en otros lugares relacionados a la comisión del delito, sirven para que en el momento del pronunciamiento de la autoridad competente, se haga de la forma más precisa y justa posible, demostrando ahí que ésta es indispensable para el seguimiento, seguridad, confiabilidad de que las muestras, huellas o evidencias lleguen al juicio oral de acuerdo con los hechos, respetando los derechos del imputado, la Constitución de la República, así como los principios que informan el proceso penal. 


\section{BIBLIOGRAFÍA}

- Bodes Torres, Jorge: Sistema de Justicia y procedimiento penal en Cuba. Editorial de Ciencias Sociales. Año 2001.

- Brito Febles, Osvaldo: Manual de Criminalística. Santa Clara, Villa Clara, Cuba. 1999.

- Candia Ferreira, José: Ponencia La fase preparatoria del juicio oral. CD Evento IV Escuela de Verano de La Habana sobre Temas penales contemporáneos, Julio del 2008.

- Carnelutti, Francesco; Cuestiones sobre el proceso penal. traducción del volumen QUESTIONI SUL PROCESO PENALE, publicado por la editorial Dott. Cesare Zuffi, Bologna, 1950.

- Claus Roxin, Maier J.B.J, Rusconi M., Guariglia F., Bruzzone G., Bertoni E., Cerletti M.: El Ministerio Público en el proceso penal. Editorial AdHoc S.R.L. 1993.

- Ferrajoli, Luigi; Derecho y Razón. Teoría del garantismo penal. Editorial Trotta.

- Fernández Romo, Rodolfo: La Prueba Pericial y el debido proceso penal. Revista Científica Equipo Federal del Trabajo. ISSN 1609 3031. Septiembre de 20011. Catalogada en Latindex desde 2005; http:// www.newsmatic.e-pol.com.ar/index.php?

- Ferrer Beltrán, Jordi; Gascón Abellán Marina, González Lagier Daniel, Taruffo Michelle: Estudios sobre la prueba. Universidad Nacional Autónoma de México. México 2006. Instituto de Investigaciones Jurídicas.

- Foucault, Michel: Vigilar y Castigar. Nacimiento de la prisión. Siglo veintiuno Editores Argentina. 1976.

- Hernández de la Torre, Rafael; Historia de la Criminalística. LCC. División de Criminalística. La Habana. 2004

- Hernández de la Torre, Rafael: Criminalística. Universidad de La Habana, Facultad de Derecho, 2006

- Posada Jeanjackes, José Angel: La Ciencia
Criminalística. 2da Edición.

- Parra Quijano Jairo: Manual de Derecho Probatorio. Décima quinta edición. Ampliada y actualizada. Editorial ABC. 2006.

- Levene Ricardo: Manual de Derecho Procesal Penal. 2da Edición. Tomo I. Ediciones Depalma. Buenos Aires Argentina. 1993.

\section{Revistas}

- Medicina Legal de Costa Rica. versión impresa ISSN 1409-0015. Med. leg. Costa Rica v.15 n.1-2 Heredia dic. 1998. Cadena y custodia de la evidencia en Costa Rica. Guillermo Hernández Ramírez

- Boletín Alerta. NUEVO CÓDIGO PROCESAL PENAL IMPIDE MOSTRAR PRUEBAS DOCUMENTALES EN ETAPA DE INVESTIGACIÓN. Lima. Perú. http://www. lozavalos.com.pe/alertainformativa/index.php

- Revista Cubana de Derecho. No. 36. JulioDiciembre 2010. Artículo Dra. Josefina Méndez López y Dra. Danelia Cuité Mustelier: La participación popular en el nuevo constitucionalismo. Unión Nacional de Juristas de Cuba.

- LA CADENA DE CUSTODIA EN EL NUEVO CODIGO DE PROCEDIMIENTO PENAL Artículo publicado en el periódico FACETA JURIDICA, Editorial Leyer, Bogotá, Enero de 2005. Por Juan Carlos Urazán Bautista

\section{Tesis Doctorales:}

- Tesis en opción al grado científico de Doctor en Ciencias Jurídicas. Autor Julio Vicente Arranz Castillero. "Cuestiones Teóricas Generales sobre la Prueba en el Proceso Penal cubano". Año 2003.

\section{Normas Jurídicas:}

- LEY 229 DE 2004-SENADO/01 DE 2003-CÁMARA

- "POR LA CUAL SE EXPIDE EL CÓDIGO DE 
PROCEDIMIENTO PENAL"

- Colombia.

- LEY No. 1970, LEY DEL 25 DE MARZO DE 1999, HUGO BANZER SUAREZ, PRESIDENTE DE LA REPUBLICA. LEY DEL CÓDIGO DE PROCEDIMIENTO PENAL. Bolivia.

- CODIGO DE PROCEDIMIENTO PENAL 2000. Ley No. 000. RO/ Sup 360 de 13 de Enero del 2000. Ecuador.

- Código procesal penal de Guatemala. 1992.

- LEY No. 406 CODIGO PROCESAL PENAL DE LA REPUBLICA DE NICARAGUA. 2001.

- Código Orgánico Procesal Penal República Bolivariana de Venezuela. 1998.

- CÓDIGO PROCESAL PENAL (Decreto Legislativo № 957). Perú.

- LEY ORGANICA DEL INSTITUTO NACIONAL DE CIENCIAS FORENSES DE GUATEMALA. INACIF

- LEY-19696 (CHILE), Fecha de Publicación:
12.10.2000, Fecha de Promulgación: 29.09.2000, Organismo: MINISTERIO DE JUSTICIA; Ultima Modificación: RECTIFICACION DIARIO OFICIAL

- Código Procesal Penal de Paraguay.

- Código de Procedimiento Penal de México.

- Código Procesal Penal El Salvador. DECRETO No. 904

- Código Procesal Penal de Costa Rica. CÓDIGO PROCESAL PENAL, Ley No. 7594, Publicada en el Alcance 31 a La Gaceta 106 de 4 de junio de 1996

- Código Procesal Penal de República Dominicana.

- CODIGO PROCESAL PENAL PERU, DECRETO LEGISLATIVO № 957

- Ley Orgánica del Organismo de Investigación Judicial (OIJ), Ley 5524 del 07/05/1974. Costa Rica. 